\title{
Avaliação do consumo de energia elétrica em estações elevatórias para abastecimento de água com diferentes configurações de sistemas
}

\section{Evaluation of electric energy consumption in pump stations for water supply with different system configurations}

Data de entrada: 26/08/2019

Data de aprovação: 03/06/2020

Luís Henrique Cardoso Alexandre ${ }^{1 *}$ | Sandra Márcia Cesário Pereira da Silva1 | Fernando Fernandes ${ }^{1}$ DOI: https://doi.org/10.36659/dae.2021.069

ORCID ID

Alexandre LHC (iD https://orcid.org/0000-0002-1966-8540
Silva SMCP (i) https://orcid.org/0000-0002-7126-7752

Fernandes F (D) https://orcid.org/0000-0003-4172-5588

\section{Resumo}

A escolha do tipo de configuração do sistema de abastecimento de água para as áreas de topografia elevadas das cidades pode se tornar uma difícil decisão, uma vez que diversas variáveis interferem no processo. A melhor escolha para o melhor sistema deve buscar a minimização de custos de implantação, operação, manutenção e garantia da eficiência, uma vez que deverá atender aos requisitos legais vigentes do local. O objetivo deste trabalho é avaliar o consumo de energia em três diferentes configurações de sistema para abastecimento de água em regiões altas. As seguintes configurações foram simuladas: utilizando estações elevatórias de água tratada com reservatório de montante, com reservatório de jusante e sem reservatório inserindo inversor de frequência. A estratégia de pesquisa foi o estudo comparativo, pois permite, por meio da exploração das semelhanças e diferenças, encontrar os princípios de variação de um determinado fenômeno ou os padrões mais gerais de um fenômeno, no caso o consumo de energia. Com a análise dos resultados obtidos para o sistema simulado concluiu-se que: a) a partir de vazão de $15 \mathrm{~m}^{3} / \mathrm{h}$ a estação elevatória controlada por inversor de frequência apresenta consumo de energia menor do que as outras configurações, que utilizam reservatórios; b) as configurações com reservatório apresentam melhor rendimento médio das bombas. É relevante ressaltar que este estudo se ateve apenas à avaliação do consumo de energia, portanto, para a definição da alternativa a ser implantada, é relevante o estudo técnico-econômico para cada localidade, considerando principalmente os fatores operacionais e disponibilidade de suporte técnico.

Palavras-chave: Abastecimento de água. Estações elevatórias. Consumo de energia. Inversor de frequência.

\section{Abstract}

The choice of system configuration type for water supplies on high levels of the cities can become a tough decision once several variables interfere on the processes. The best system should seek to minimize the energy consumption and other inputs, and to minimize deployment, operation and maintenance costs, maintaining a good efficiency, since it must follow local legal requirements. The aim of this study is to evaluate the energy consumption in three

\footnotetext{
${ }^{1}$ Universidade Estadual de Londrina - Londrina - Paraná - Brasil.

* Autor correspondente: luish_alexandreahotmail.com.
} 
different system configurations for high level zones supply systems using pump stations with upstream reservoir connected to the system distribution, with upstream reservoir not connected to the system distribution and without reservoir inserting variable speed drives. The research strategy was a comparative study, through the exploration of similarities and differences, finding the principles of variation of a given phenomenon or general patterns of a phenomenon, in this case energy consumption. With the analysis results it was concluded that: a) from a $15 \mathrm{~m}^{3}$ / ha flow controlled rate by variable speed drive presented lower power consumption than the other configurations, which used reservoirs; $B$ ) configurations with reservoir presented better performance of the pumps; c) pump head proved to be one of the main factors for increased energy consumption, as higher the pump head was, it demanded more power pumps. In this way, the use of pipelines of larger diameters, although more expensive, can have its investment reduced due to the electric energy economy throughout the design period. It is important to highlight that this study was focused only on the energy consumption evaluation; therefore, to choose the best alternative to be implemented, the technical-economic study for each location is important, mainly considering the operational factors and technical support availability.

Keywords: Water supply system. Pump stations. Electric energy consumption. Variable speed drive.

\section{INTRODUÇÃO}

A redução do consumo de energia tem sido amplamente defendida, devido aos seus elevados custos, limitação das matrizes energéticas e questões ambientais. No Brasil, a energia elétrica tem como característica seu alto custo, além dos recorrentes riscos de racionamento em períodos de seca.

O setor industrial, maior consumidor de energia, tem buscado cada vez mais alternativas para otimizar sua eficiência energética. Entre os fatores mais utilizados, destacam-se a troca de equipamentos antigos por novos mais eficientes, produção de energia local com métodos alternativos sustentáveis e redução do consumo em horários de pico.

Em sistemas de abastecimento de água, os principais custos envolvidos são os referentes à implantação e operação. Na implantação, devem ser feitos investimentos em captação, adução, reservação e rede de distribuição, enquanto os principais custos com operação são referentes à mão de obra e energia elétrica para funcionamento do sistema. No Brasil e no mundo, o consumo de energia em sistemas de abastecimento de água recebe especial atenção por ser, em mui- tos casos, a segunda maior despesa das empresas de saneamento, perdendo apenas para o pagamento de pessoal. Em muitos casos, os gastos com energia de bombeamento ultrapassam os custos de investimento das instalações, ao longo da vida útil dos projetos (GOMES, 2009).

Visto o elevado consumo de energia elétrica em sistemas de abastecimento de água, medidas que induzem maior economia e aumento da eficiência energética são importantes para empresas públicas e privadas de saneamento. Algumas medidas usualmente tomadas visando ao aumento da eficiência energética são a troca de bombas por modelos de maior eficiência, troca de tubulações antigas por novas que apresentam menor perda de carga, etc.

Tsutiya (2001) afirma que as despesas com energia elétrica representam o segundo ou terceiro item de maior custo para as empresas de saneamento brasileiras, e que sua redução pode se dar, entre outras maneiras, por meio da alteração do sistema operacional, a partir da alteração do sistema bombeamento/reservação e utilização de 
variadores de rotação das bombas, e por meio da automação do sistema de abastecimento de água.

De acordo com Costa (2009), modificações nas bombas ou mudanças operacionais podem resultar em redução significativa nos custos com energia elétrica. Simulações de diferentes controles operacionais de acordo com os níveis dos reservatórios ou a utilização de inversores de frequência podem levar à solução ótima que minimiza os custos operacionais de um sistema.

Visto os altos custos relacionados a projetos de saneamento, para que sejam executadas mudanças que possam aumentar a eficiência, produtividade, confiabilidade e diminuir os custos de operação, uma análise de custo-benefício é necessária para que os gestores de sistemas de abastecimento público possam verificar quanto tempo é necessário para o retorno do investimento (BARRY, 2007).

Nos sistemas de abastecimento convencionais, em que as velocidades das bombas não se alteram, não é impossível ajustar o funcionamento dos conjuntos moto-bomba à variação de consumo dos usuários. Dessa forma, não há otimização do fornecimento de água, além de o sistema operar com uma pressão maior do que a necessária, provocando desperdício de energia, além de causar danos às redes, canalizações auxiliares e equipamentos nela instalados (YANG et al., 2010).

As bombas com inversor de frequência têm sido utilizadas para distribuição de água para locais elevados, substituindo a construção de reservatórios para abastecimento desses locais. A utilização de inversor de frequência possibilita ajustar o funcionamento dos conjuntos moto bomba, variando a velocidade de rotação do conjunto de acordo com a demanda de água necessária para o abastecimento, podendo, dessa forma, reduzir os custos energéticos de bombeamento (CARVALHO, 2012).

Shankar et al. (2016) examinaram vários métodos para melhoramento da eficiência de sistemas de bombeamento com bombas centrífugas. Os autores citam que tradicionalmente o aumento da eficiência pode ser alcançado com a utilização de inversores de frequência, porém cerca de $30 \%$ a $50 \%$ da energia pode ser economizada com uma escoIha correta de bombas e equipamentos com maior eficiência, enquanto aproximadamente de $15 \%$ a $25 \%$ de economia de energia pode ser alcançado pelo dimensionamento adequado das tubulações do sistema. As perdas em sistemas com inversores de frequência são geralmente influenciadas por características do projeto, da fabricação, e pela velocidade operacional do motor elétrico. As perdas mínimas nesses sistemas são de aproximadamente $5 \%$ a $8 \%$ quando operados na velocidade de projeto. Quando os sistemas são operados em velocidades diferentes das de projeto, sua eficiência cai drasticamente, e as perdas variam de $10 \%$ a $20 \%$.

Este trabalho tem como objetivo comparar o consumo de energia de três diferentes configurações de sistema de abastecimento de zonas altas, operando com controle por inversores de frequência, por reservatórios de jusante e por reservatórios de montante.

\section{METODOLOGIA}

\subsection{Configurações dos sistemas de abastecimento de zonas altas}

Este trabalho avaliou 3 diferentes configurações de sistemas para abastecimento de zonas altas, a fim de comparar o consumo energético dos sistemas de bombeamento para os diferentes casos. As configurações analisadas foram: bombeamento direto para reservatório de montante que abastece a rede; bombeamento para abastecimento de rede e reservatório de jusante e pressurização da rede por meio de elevatória com inversor de frequência.

$\mathrm{Na}$ configuração com reservatório de montante, o sistema de bombeamento de água recalca diretamente para um reservatório por meio de 
adutora virgem, sendo o reservatório responsável pelo abastecimento da rede de distribuição. Esse sistema é amplamente aplicado devido à sua maior flexibilidade. Como a adutora não é conectada diretamente à rede, ela pode suportar maiores pressões internas, permitindo a aplicação desse sistema em locais onde há maior desnível entre a Estação Elevatória e as cotas mais elevadas a serem abastecidos.

No caso de sistemas com reservatório de jusante, o bombeamento é feito diretamente para a rede de distribuição, atendendo ao consumo da população, e o volume não consumido é armazenado. Quando o reservatório atinge seu nível máximo, o sistema de bombeamento é desligado e a rede é abastecida somente pelo reservatório até que este atinja seu nível mínimo e o recalque se reinicie. É recomendada a implantação de uma tubulação principal para o recalque da elevatória ao reservatório e a interligação da rede nesta tubulação, porém há casos em que a rede é conectada à elevatória sem qualquer alteração.

Para o terceiro caso, sistema com pressurização da rede e inversor de frequência, não há reservatório após a elevatória, sendo o abastecimento feito apenas pelo sistema de bombeamento, com a utilização de inversor de frequência. $O$ inversor de frequência garante que a bomba opere em diferentes rotações de acordo com a necessidade de vazão a ser recalcada momentaneamente. 0 sistema de bombeamento pode ser programado para que a pressão ou a vazão na saída na bomba sejam constantes. Com utilização de um pressostato, o sistema pode ser configurado para que seja mantida a pressão mínima na rede.

\subsection{Cálculo das vazões de projeto e dimensionamento de tubulações e reservatórios}

Em sistemas de abastecimento, a vazão de projeto é calculada de acordo com as previsões de crescimento populacional e o consumo a serem atendidos. O dimensionamento dos sistemas é feito de acordo com a vazão máxima a ser atendi$\mathrm{da}$, levando-se em conta a hora de maior consumo do dia de maior consumo de água. Para as simulações hidráulicas, foi utilizada uma curva de consumo horário que distribui o consumo diário de forma realista, com baixo consumo durante a madrugada e maior consumo no período da tarde. Na delimitação do trabalho não foram consideradas variações de consumo mensais e anuais.

Nas configurações com reservatório, a capacidade de reservação necessária foi tomada como igual ou maior que $1 / 3$ do volume aduzido no dia de maior consumo.

Adotaram-se como limites as velocidades mínimas de $0,6 \mathrm{~m} / \mathrm{s}$ e máxima de $3,0 \mathrm{~m} / \mathrm{s}$ tanto para o barrilete como para a tubulação de recalque, conforme recomendado pela NBR 12214/1992, sendo o dimensionamento feito buscando velocidades mais baixas, a fim de minimizar as perdas de carga na tubulação de recalque.

Com as vazões a serem simuladas e os diâmetros das tubulações para os diferentes casos, pode ser feito o cálculo da altura manométrica dos sistemas.

\subsection{Cálculo das alturas manométricas e escolha das bombas}

Para o cálculo da altura manométrica e escolha das bombas são necessários dados a respeito da geometria do sistema, vazão a ser recalcada e perda de carga na tubulação. Inicialmente foi feito o cálculo das perdas de carga nos sistemas.

Para o cálculo das perdas de carga nas tubulações, foi utilizada a fórmula universal. A altura manométrica do sistema de bombeamento denominada $\mathrm{Hm}$ é função da altura estática da elevação do fluído e das perdas de carga existentes no circuito. É necessário o cálculo da altura manométrica para cada vazão a ser recalcada para 
todas as configurações de sistema a serem analisadas. A escolha da bomba é feita por meio de catálogos de fabricantes.

\subsection{Utilização do software WaterGEMS}

Neste trabalho foram feitas simulações hidráulicas com o software WaterGEMS V8i, por meio do qual é possível obter diversos dados acerca do funcionamento de sistemas de abastecimento, como variação do consumo, vazão nas tubulações, pressão nos nós, nível dos reservatórios, funcionamento das estações elevatórias, eficiência das bombas, gastos com energia, entre outros.

Neste programa são inseridos dados a respeito da fonte de abastecimento, topologia do sistema, estações de bombeamento, tubulações, reservatórios, consumo de água e custos de energia.

As bombas foram inseridas no software por meio de suas curvas características, obtidas em catálogos de fabricantes. Além das curvas, da altura manométrica em função da vazão, também foram inseridas as curvas de eficiência.

Para as tubulações, foram inseridos dados como material, diâmetro, rugosidade e comprimento. Foram inseridas tubulações que representam um anel de abastecimento de rede ou da adutora, quando esta é existente no sistema.

Nas configurações com reservatório, este foi inserido logo após o ponto mais distante da EET. Foram inseridas as dimensões do reservatório, da base em que o reservatório é assentado, além dos níveis operacionais. Considerou-se para todos os cenários a instalação de reservatórios elevados cilíndricos em fibra de vidro (PRFV), assentados sobre base com estrutura de concreto. As dimensões dos reservatórios para as diferentes capacidades dimensionadas foram obtidas de acordo com catálogo de fabricante. Usualmente, a base para reservatórios elevados (REL) costuma ter altura de 3,0, 6,0 ou 9,0m. As bases em cada cenário foram definidas de acordo com a altura do reservatório, de forma a garantir a pressão mínima de 10 m.c.a. no ponto da rede mais elevado e próximo ao reservatório.

O consumo de água foi distribuído em diferentes nós. Além do volume consumido, é inserida no programa a curva de distribuição do consumo durante o dia, já contemplando os coeficientes k1 e k2.

No Software WaterGEMS foram inseridas as tarifas referentes ao consumo de energia das bombas; dessa forma, o programa efetuou o cálculo dos gastos com operação do sistema. As tarifas utilizadas foram as tarifas vigentes para clientes do subgrupo A4 (2,3 a $25 \mathrm{kV}$ ), enquadrados na Modalidade Tarifária Azul. Segundo a Resolução ANEEL Nº 2.096, de 21 de junho de 2016, as tarifas sem os impostos ICMS e PIS/COFINS referentes ao consumo em horário de ponta são de $R \$ 0,39683 / \mathrm{kWh}$ e $\mathrm{R} \$ 0,27930$ fora de ponta, sendo o horário de ponta das 18:00 às 21:00 horas. Nos sistemas com reservatórios, as bombas foram configuradas para não funcionar nos horários de ponta.

Foram feitas simulações dos sistemas para 120 horas de operação. Utilizando um período estendido de simulação, são minimizados os efeitos da variação diária no funcionamento das bombas. Nesse período, o software calcula as variações horárias no consumo, variação no nível dos reservatórios, horários de funcionamento das bombas, vazão e volume recalcados, eficiência das bombas, energia consumida e custos referentes à energia, entre outros dados.

Para avaliar qual é a configuração do sistema com menor consumo de energia, foram analisados e comparados os resultados obtidos com relação ao custo por volume bombeado, além do custo e consumo anuais com energia. 


\subsection{Simulações com sistemas esquemáticos}

Para as simulações foi definido um sistema esquemático básico, em que as características básicas das três configurações de sistema pudessem ser avaliadas de forma semelhante. Para isso, foi estabelecida uma topografia genérica, representando o desnível e a distância entre as fontes de abastecimento e áreas mais altas a serem atendidas, considerando casos reais já projetados na atividade profissional, resultando em diferença de cota de 20 metros e distância de 1.000 m entre a EET e o ponto mais distante da rede.

Foram estabelecidas faixas de vazão de abastecimento com objetivo de representarem sistemas de pequeno e médio porte, com população atendida de 250 pessoas a 3.330 pessoas. As populações foram definidas considerando os principais volumes de reservatórios em PRFV existentes comercialmente.
Para representar a fonte de abastecimento do sistema, correspondente ao reservatório, estação de tratamento de água (ETA) ou rede de abastecimento à montante da estação elevatória, foi inserida uma fonte de água infinita, já que foi considerado que haverá disponibilidade hídrica para o funcionamento do sistema. Para cada uma das 3 configurações de sistema avaliadas e faixas de vazão foram feitos o dimensionamento das tubulações de barrilete e de recalque, dimensionamento do reservatório nas configurações em que este está presente, cálculo da altura manométrica e escolha das bombas. Após obtenção desses parâmetros, estes foram inseridos no programa computacional para realização das simulações.

A Fig. 1 apresenta os esquemas simulados no software WaterGEMS para as diferentes faixas de vazão.
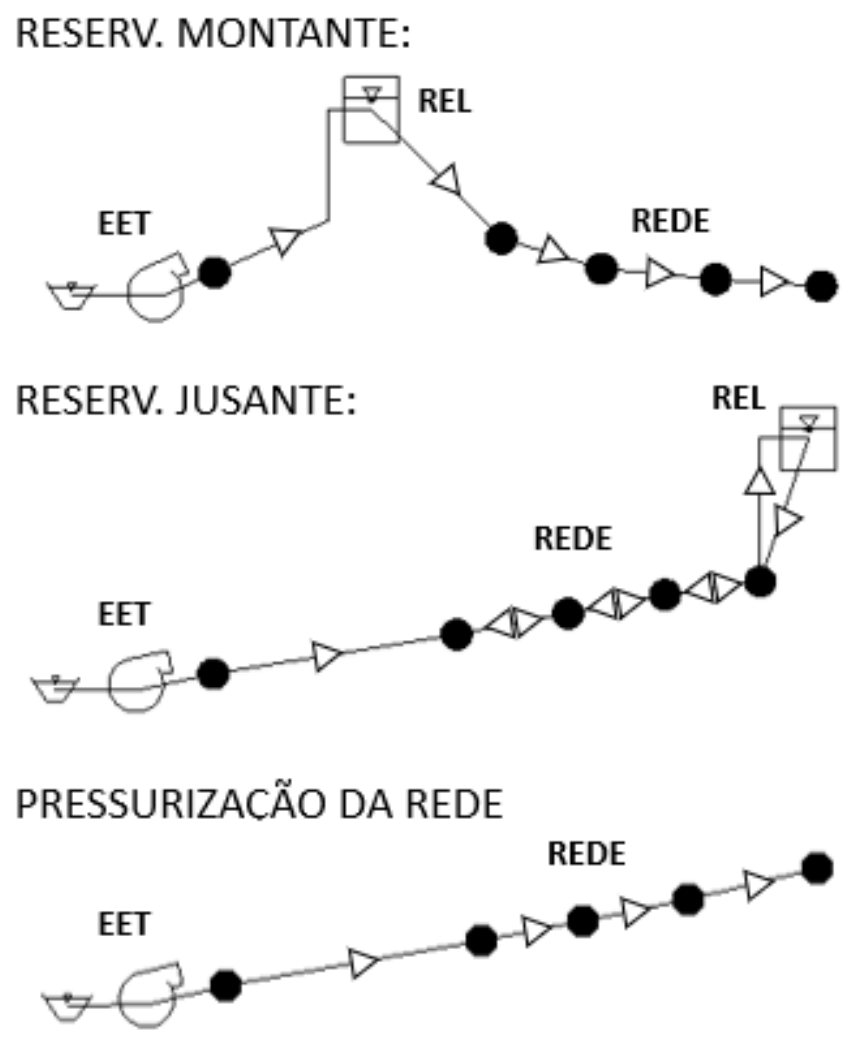

Figura 1 - Sistemas esquemáticos das diferentes configurações estudadas 
A estação de bombeamento foi inserida na cota 0,00 dos sistemas esquemáticos. Na configuração do sistema com inversor de frequência, a bomba foi programada para variar as suas rotações de forma que seja mantida a pressão mínima de 10 m.c.a. no ponto mais distante da rede. Já nas configurações com reservatórios, a operação da bomba foi definida de forma que esta entre em operação quando o reservatório se esvazia à metade de sua altura e parando quando este atinge sua capacidade máxima.

\section{RESULTADOS E DISCUSSÃO}

3.1 Cálculo das vazões de projeto, dimensionamento dos reservatórios e escolha das bombas

Na Tabela 1 apresentam-se os parâmetros básicos de projeto calculados para as simulações do sistema esquemático, com vazão de projeto, diâmetros nominais (DN) das tubulações e capacidade do reservatório. Os valores calculados para diâmetro dos tubos e volume do reservatório foram aproximados para os existentes comercialmente.

Tabela 1 - Parâmetros básicos de projeto calculados para o sistema estudado.

\begin{tabular}{|c|c|c|c|c|}
\hline $\begin{array}{c}\text { População abastecida } \\
\text { (hab.) }\end{array}$ & $\begin{array}{c}\text { Vazão de projeto } \\
\left(\mathbf{m} \mathbf{m}^{\mathbf{h}} \mathbf{h}\right.\end{array}$ & $\begin{array}{c}\text { DN do barrilete } \\
(\mathbf{m m})\end{array}$ & $\begin{array}{c}\text { DN da tubulação de } \\
\text { recalque (mm) }\end{array}$ & $\begin{array}{c}\text { Cap. do reservatório } \\
\left(\mathbf{m}^{\mathbf{3}} \mathbf{)}\right.\end{array}$ \\
\hline 250 & 2,81 & 32 & 50 & 15 \\
\hline 500 & 5,63 & 50 & 50 & 30 \\
\hline 1000 & 11,25 & 65 & 75 & 60 \\
\hline 1650 & 18,56 & 80 & 100 & 100 \\
\hline 2000 & 22,50 & 80 & 100 & 120 \\
\hline 2500 & 28,13 & 100 & 100 & 150 \\
\hline 3330 & 37,46 & 100 & 150 & 200 \\
\hline
\end{tabular}

A Tabela 1 mostra que as faixas de vazão analisadas variam de 2,81 a $37,46 \mathrm{~m}^{3}$, o DN do barrilete do sistema de bombeamento de DN32 a DN100, a tubulação de recalque de DN50 a DN150 e os reservatórios de 15 a $200 \mathrm{~m}^{3}$.

Para o cálculo da altura manométrica dos cenários com pressurização da rede, foi considerado que o sistema de bombeamento deveria garantir a pressão mínima na rede de 10 m.c.a. no ponto mais alto e distante da EET. Já para os cenários com reservatórios, o sistema de bombeamento deveria garantir o abastecimento do REL, enquanto o reservatório também deveria garantir pressão mínima na rede de 10 m.c.a. no ponto mais alto e distante da EET, sendo neste caso o ponto mais próximo do REL. A Tabela 1 apresenta as dimensões dos reservatórios utilizados.

As dimensões utilizadas são referentes ao catálogo comercial de fabricantes brasileiros existen- tes no mercado. A altura de entrada no reservatório é a soma da altura útil e altura da base dos reservatórios. Para os reservatórios de menor capacidade, foram consideradas bases com 9,00m de altura, a fim de garantir a pressão mínima de 10m.c.a. considerando as variações de nível; já nos reservatórios maiores, pode ser considerada uma altura da base de $6,00 \mathrm{~m}$, devido à maior altura do nível de água.

Para uniformização dos resultados, em todos os cenários foram empregadas bombas centrífugas de um fabricante disponível no mercado brasileiro, que permite a usinagem de rotores com diâmetro otimizado para a curva do sistema calculado. Por isso, sobre as curvas do catálogo foram traçadas curvas que passassem pelo ponto de operação dos sistemas calculados. Além das curvas de operação, foram inseridas no software as curvas de eficiência das bombas. 


\subsection{Resultados das simulações}

Nas Fig. 2 a 5 são ilustrados os resultados obtidos, no software WaterGEMS, para as três configurações, considerando a vazão de $28,1 \mathrm{~m}^{3} / \mathrm{h}$, para facilitar a comparação entre elas. Na Fig. 2, os resultados são dos horários de funcionamento da bomba e a vazão recalcada, e na Fig. 3 a altura manométrica. Na Fig. 4 apresenta-se o consumo de energia das bombas e na Fig. 5 o gasto financeiro com energia elétrica, considerando os valores vigentes de tarifas.

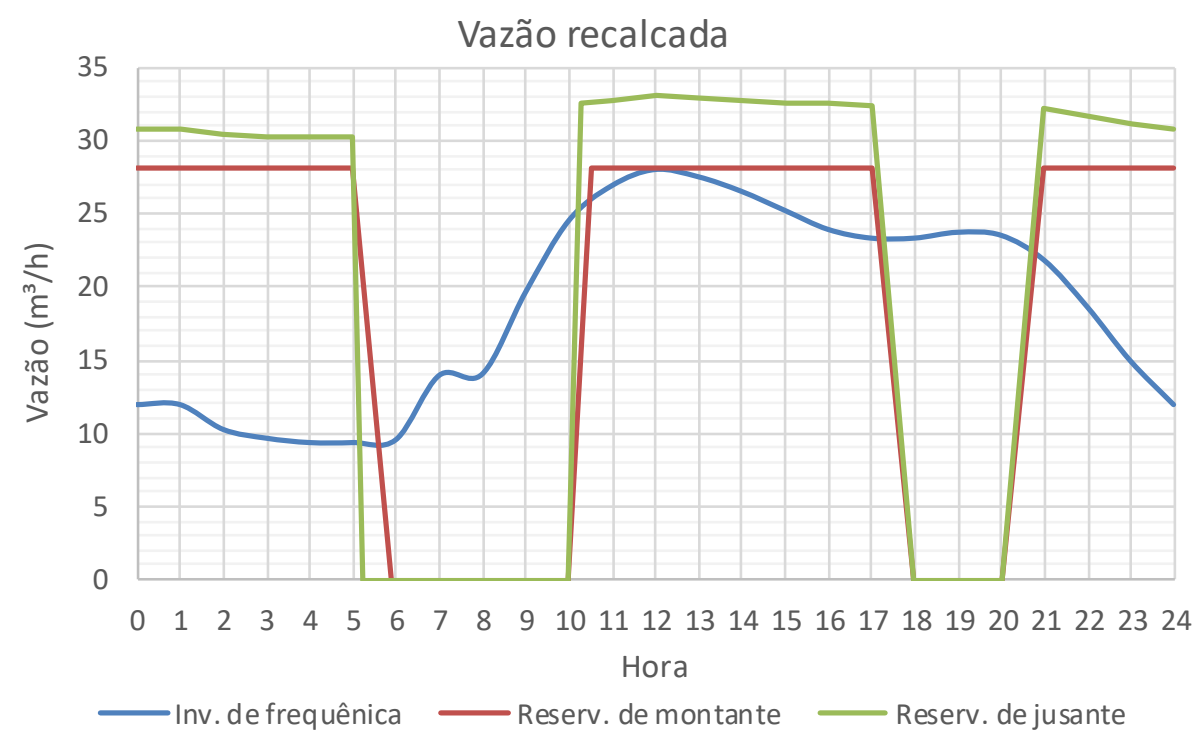

Figura 2 - Variação da vazão recalcada na simulação com vazão de 28,1 $\mathrm{m}^{3} / \mathrm{h}$ para as configurações estudadas

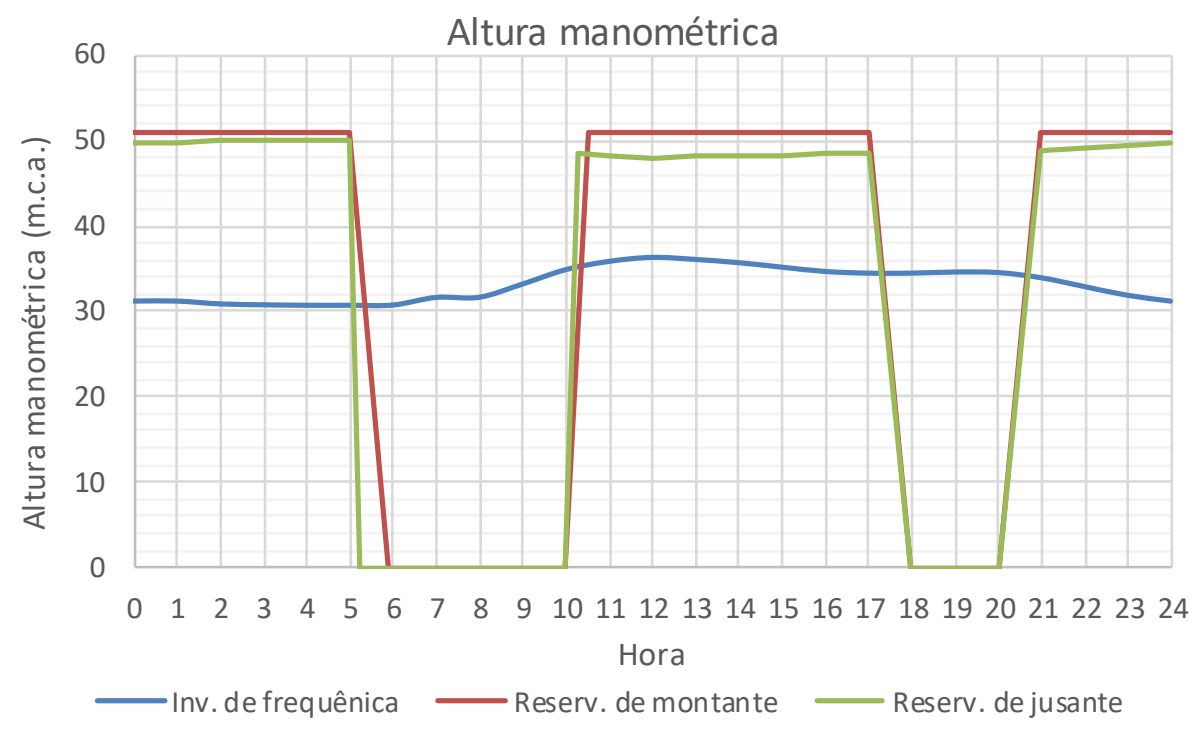

Figura 3 - Variação da altura manométrica das bombas na simulação com vazão de $28,1 \mathrm{~m} / \mathrm{h}$ para as configurações estudadas 


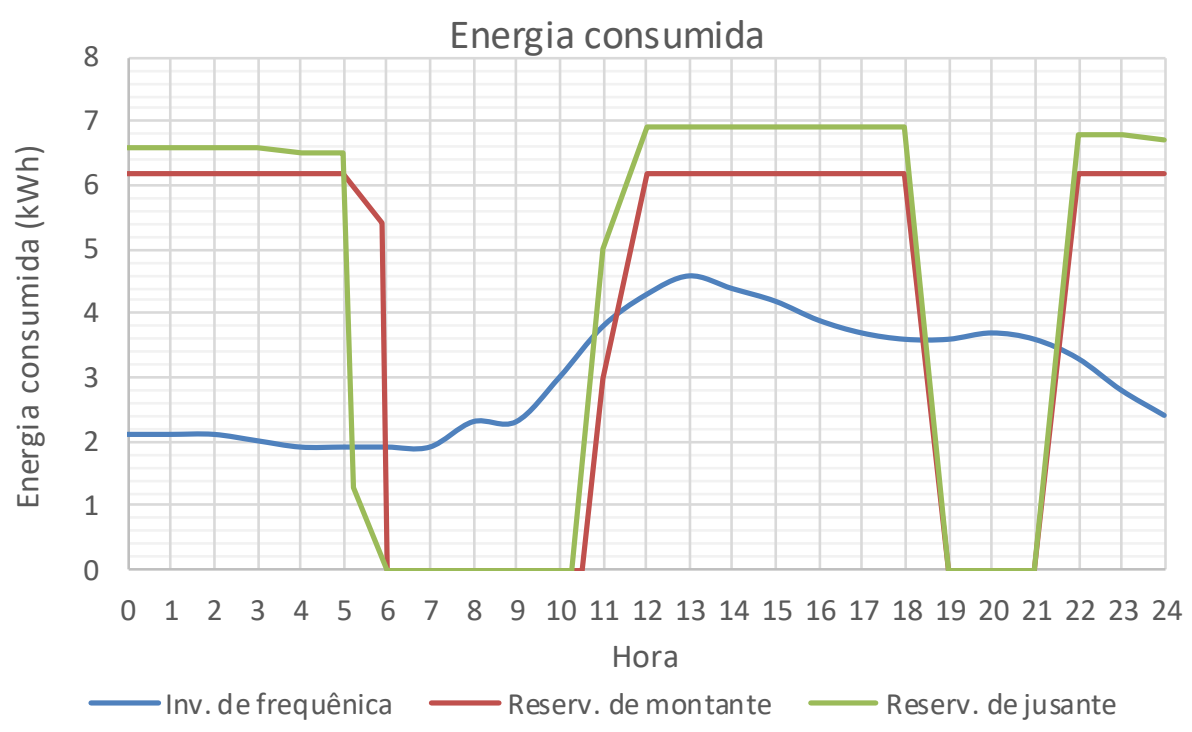

Figura 4 - Consumo de energia das bombas para vazão de projeto de $28,1 \mathrm{~m}^{3} / \mathrm{h}$ e todas as configurações simuladas

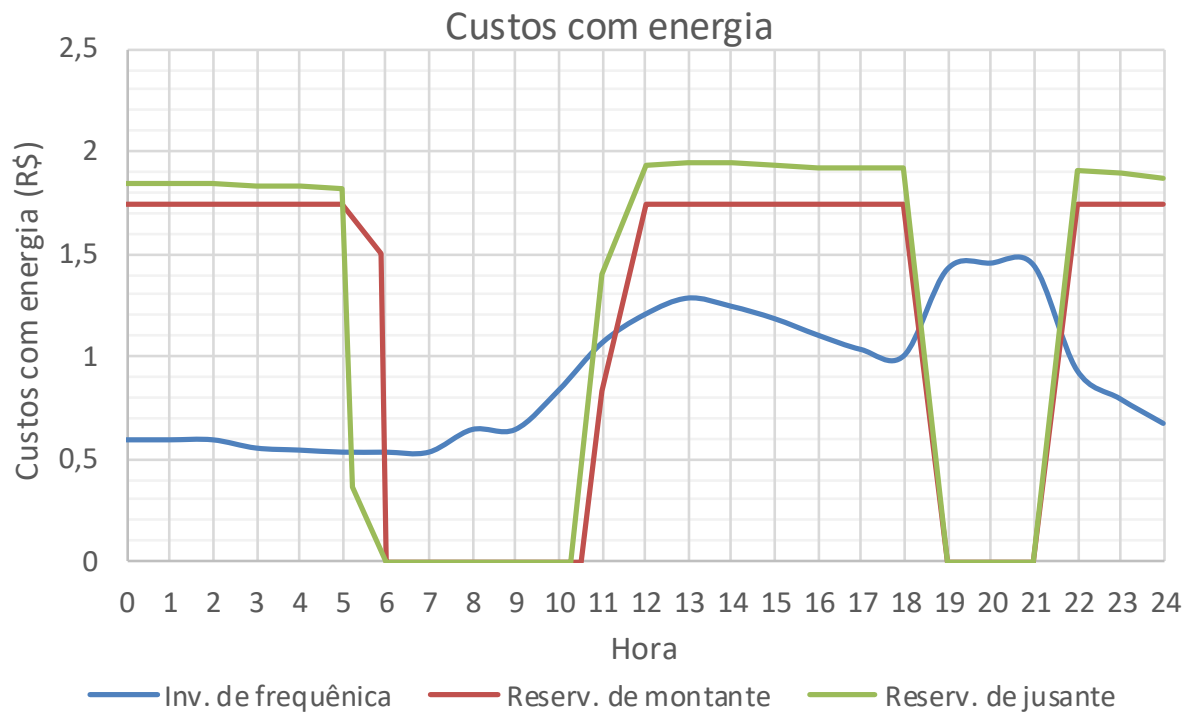

Figura 5 - Gastos com energia das bombas para vazão de projeto de $28,1 \mathrm{~m}^{3} / \mathrm{h}$ e todas as configurações simuladas

Verifica-se que nos sistemas com reservatórios as bombas ficam inoperantes nos horários com o custo energia $\mathrm{kw} / \mathrm{h}$ mais caro, conforme foram programadas para não entrarem em operação, e durante o período da manhã, quando o consumo é menor, e os reservatórios conseguem manter o abastecimento.

Na Fig. 6 apresenta-se o consumo anual de energia dos diferentes sistemas para as diferentes faixas de vazão analisadas. 


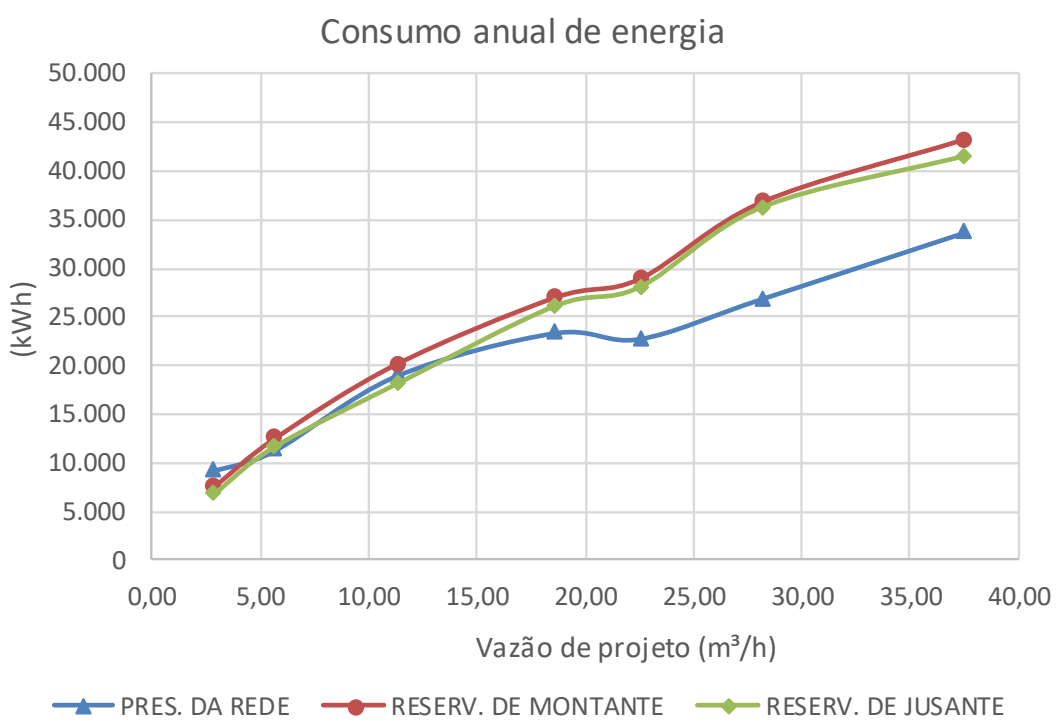

Figura 6 - Consumo anual de energia em função da vazão de projeto para todas as configurações simuladas

Observa-se que para a menor vazão analisada $\left(2,81 \mathrm{~m}^{3} / \mathrm{h}\right)$ a configuração com menor consumo energético é a com reservatório de jusante, sendo o consumo energético anual da configuração com reservatório de montante é $10 \%$ maior, enquanto o consumo da configuração com pressurização da rede é $36 \%$ maior. Já para a maior faixa de vazão analisada, a configuração de sistema que apresenta o menor consumo energético é a pressurização da rede. Para este caso, o consumo do sistema com reservatório de jusante é $23 \%$ maior, enquanto com reservatório de montante é $28 \%$ maior.

Na Fig. 7 mostra-se a variação do custo anual com energia para funcionamento das EETs.

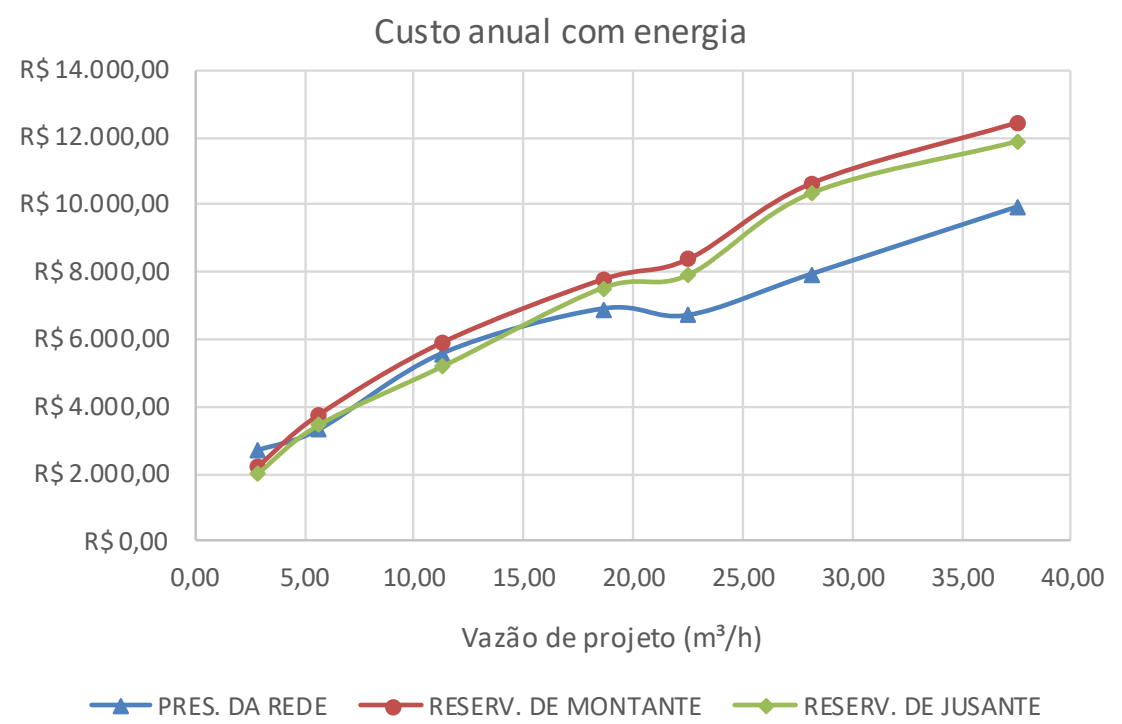

Figura 7 - Custo anual com energia em função da vazão de projeto para todas as configurações estudadas 
Para a menor faixa de vazão analisada $(2,81$ $\mathrm{m}^{3} / \mathrm{h}$ ), a configuração com reservatório de jusante, mais econômica, tem um custo anual com energia elétrica para operação de $\mathrm{R} \$ 2.022,10$. Em seguida, a configuração com reservatório de montante tem um custo de $\mathrm{R} \$ 2.222,85$ e a com inversor de frequência demanda $\mathrm{R} \$ 2.708,30$ a cada ano. Neste caso, durante um período de projeto de 20 anos, a economia de energia entre um sistema com reservatório de jusante e com inversor de frequência é de $R \$ 13.724,00$. Esse valor é bastante inferior ao custo de implantação de um reservatório em PRFV de $15 \mathrm{~m}^{3}$, que pode alcançar os $\mathrm{R} \$ 150.000,00$ quando considerados também os custos da estrutura de base do REL.

Já para a maior faixa de vazão estudada $(37,46$ $\mathrm{m}^{3} / \mathrm{h}$ ), o sistema controlado por inversor de frequência tem o menor gasto com energia, demandando anualmente $\mathrm{R} \$$ 9.946,25 (consumo de 33.682,20 kWh), enquanto para o sistema com reservatório de jusante é de $R \$ 11.877,10$ (consumo de $41.427,50 \mathrm{kWh}$ ) anuais e $\mathrm{R} \$ 12.446,50$ (consumo de 43.208,70 kWh) para o sistema com reservatório de montante. Para um período de projeto de 20 anos, a economia com energia elétrica quando utilizado um sistema com inversor de frequência em relação a um sistema com reservatório de montante é de $\mathrm{R} \$ 50.005,00$.

Apesar do menor gasto com energia elétrica apresentado pelo uso do inversor de frequência, devem ser levados em conta pelas empresas de saneamento, nas tomadas de decisões, os maiores riscos, relacionados principalmente a quedas de energia. Com a falta de energia elétrica, o bombeamento é interrompido, causando desabastecimento imediato da rede, que, além de prejudicar o consumo d'água, pode facilitar infiltrações e contaminação da rede. Nas configurações com reservatórios, o desabastecimento não ocorre de imediato, pois os mesmos mantêm um volume armazenado que é utilizado até a normalização do sistema. Além disso, quedas de energia podem causar danos ao inversor de frequência, necessitando de reparos que requerem mão de obra especializada existente apenas em grandes centros urbanos.

Uma das causas do maior consumo de energia pelos sistemas com reservatórios é a maior altura manométrica a ser vencida pelo sistema de bombeamento, principalmente devido ao desnível geométrico imposto pelo reservatório (REL) para cada faixa de vazão simulada. Com inversores de frequência, pode-se configurar a EET para que a pressão mínima na rede no ponto mais alto seja o limite recomendado de 10 m.c.a., enquanto com os reservatórios a pressão mínima deve ser suficiente para garantir o enchimento do reservatório, que além de estar apoiada sobre uma base elevada tem sua entrada pela parte superior. $\mathrm{Na}$ Fig. 8 apresenta-se a variação da altura manométrica para as diferentes faixas de vazão analisadas.

A altura manométrica para o sistema com reservatório de montante para a vazão de $37,5 \mathrm{~m}^{3} / \mathrm{h}$, que representa o caso com a maior altura de entrada no reservatório $(6,00 \mathrm{~m}$ de base e $15,41 \mathrm{~m}$ de altura do reservatório), é de 44,89m.c.a.; já a altura manométrica para o sistema inversor de frequência e mesma vazão é de 30,73m.c.a. Reservatórios mais largos e baixos poderiam diminuir a altura a ser vencida pela bomba, porém necessitariam de bases maiores e mais dispendiosas de serem construídas. Reservatórios de fibra de vidro, com maior largura, também apresentam maior dificuldade de transporte.

A Fig. 9 mostra a potência requerida pelas bombas para as diferentes faixas de vazão. 


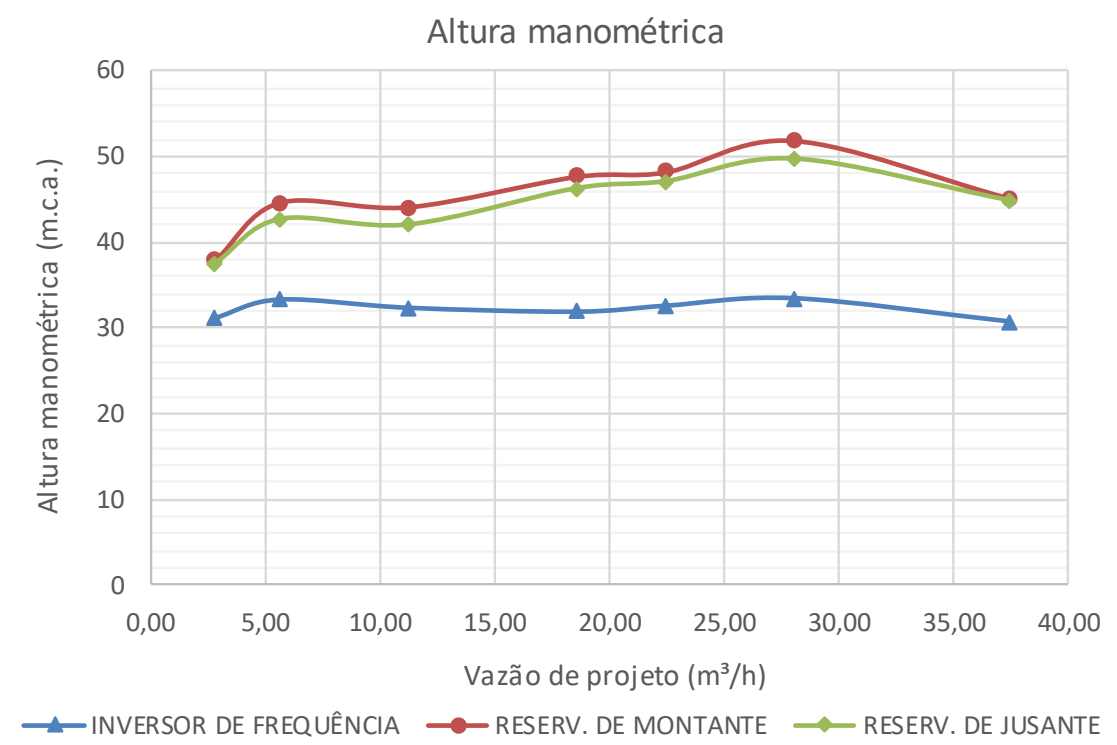

Figura 8 - Variação de altura manométrica com a vazão de projeto para todas as configurações simuladas

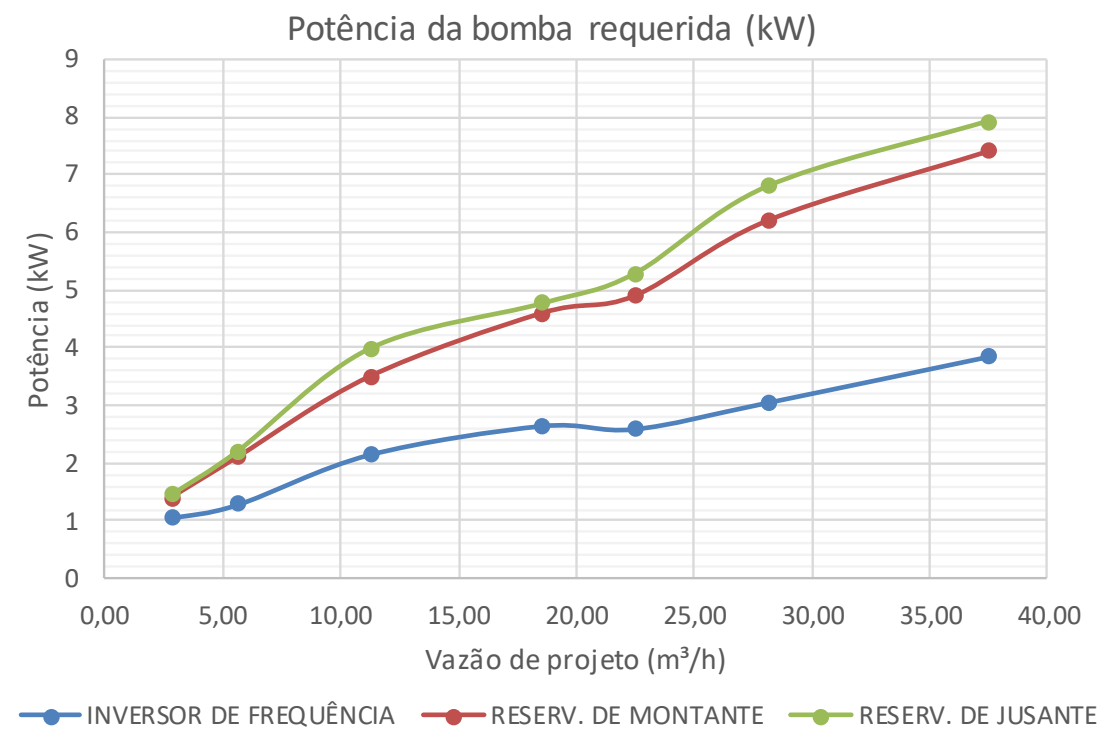

Figura 9 - Potência requerida de bombas de acordo com as vazões para todas as configurações simuladas

Verifica-se que a potência requerida pelas bombas nos sistemas com reservatórios é maior do que quando o sistema é controlado por inversor de frequência, justificando o maior consumo energético desses sistemas. Com a menor vazão estudada $\left(2,81 \mathrm{~m}^{3} / \mathrm{h}\right)$, essa diferença é pequena; nesse caso, as bombas dos sistemas com reservatórios demandam uma potência de
$1,4 \mathrm{~kW}$, enquanto a bomba com inversor de frequência demanda $1,0 \mathrm{~kW}$. Já para a maior vazão $\left(37,46 \mathrm{~m}^{3} / \mathrm{h}\right)$, os sistemas com reservatórios de montante e jusante requerem potências de 7,9 e $7,4 \mathrm{kw}$ respectivamente, enquanto a bomba operando com inversor de frequência requer $3,85 \mathrm{~kW}$, cerca de $49 \%$ do requerido pela bomba para o sistema com reservatório de montante. 
Observou-se que as bombas centrífugas analisadas costumam apresentar baixa eficiência para pequenas vazões, sendo mais eficientes com vazões maiores. A

Fig. 10 apresenta a eficiência média das bombas.

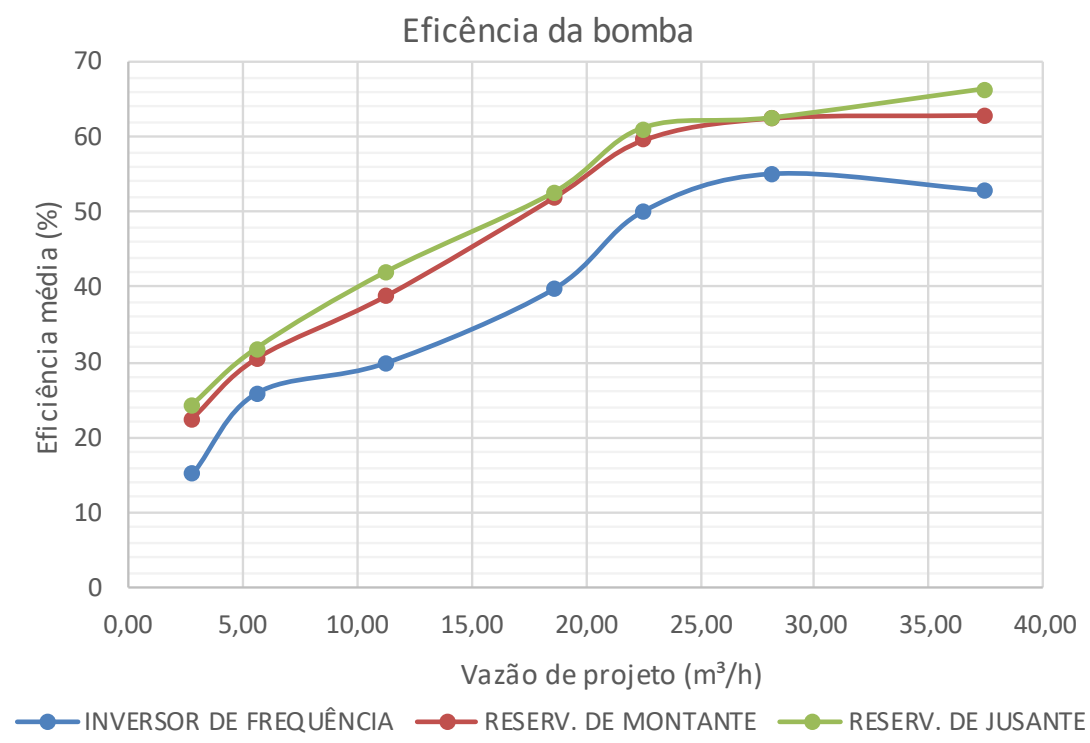

Figura 10 - Eficiência média das bombas selecionadas de acordo com a vazão para todas as configurações simuladas

Para a menor vazão analisada $\left(2,81 \mathrm{~m}^{3} / \mathrm{h}\right)$, a eficiência das bombas quando há reservatório foi na ordem de $24 \%$, enquanto para uso de inversor de frequência foi de $15 \%$. Já para a maior vazão $\left(37,46 \mathrm{~m}^{3} / \mathrm{h}\right)$, a eficiência das bombas é consideravelmente melhor, sendo cerca de $65 \%$ para os sistemas com reservatórios e $53 \%$ quando empregado inversor de frequência.

A menor eficiência média do sistema com inversor de frequência é devida à grande variação do ponto de operação da bomba durante seu funcionamento. Com a variação da rotação e o deslocamento das curvas de operação, a bomba tende a trabalhar com melhor eficiência nas condições de maior consumo, condição para qual foi dimensionada, e com menor eficiência quando está sendo pouco exigida. Na Fig. 11 apresenta-se a variação da eficiência das bombas durante seu funcionamento, para a vazão de projeto de $28,1 \mathrm{~m}^{3} / \mathrm{h}$.

Na Fig. 11, observa-se que os sistemas com reservatórios apresentam eficiência da bomba constantes, enquanto com o inversor de frequência há significativa variação.

A disparidade observada entre a eficiência das bombas de maior e menor vazão se reflete em uma grande variação do custo unitário por volume bombeado para as diferentes faixas de vazão. Na Fig. 12 apresenta-se o custo unitário médio em $\mathrm{R} \$ / 1000 \mathrm{~m}^{3}$ para as diferentes faixas de vazão. 


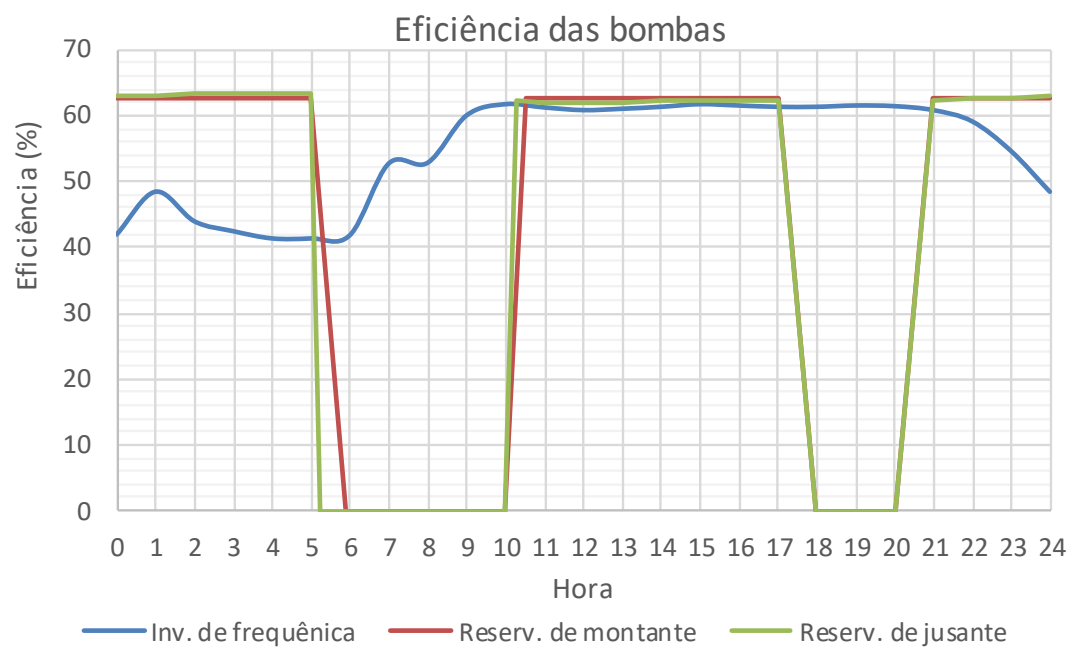

Figura 11 - Variação da eficiência das bombas com o tempo para vazão de projeto de $28,1 \mathrm{~m}^{3} / \mathrm{h}$ para todas as configurações simuladas

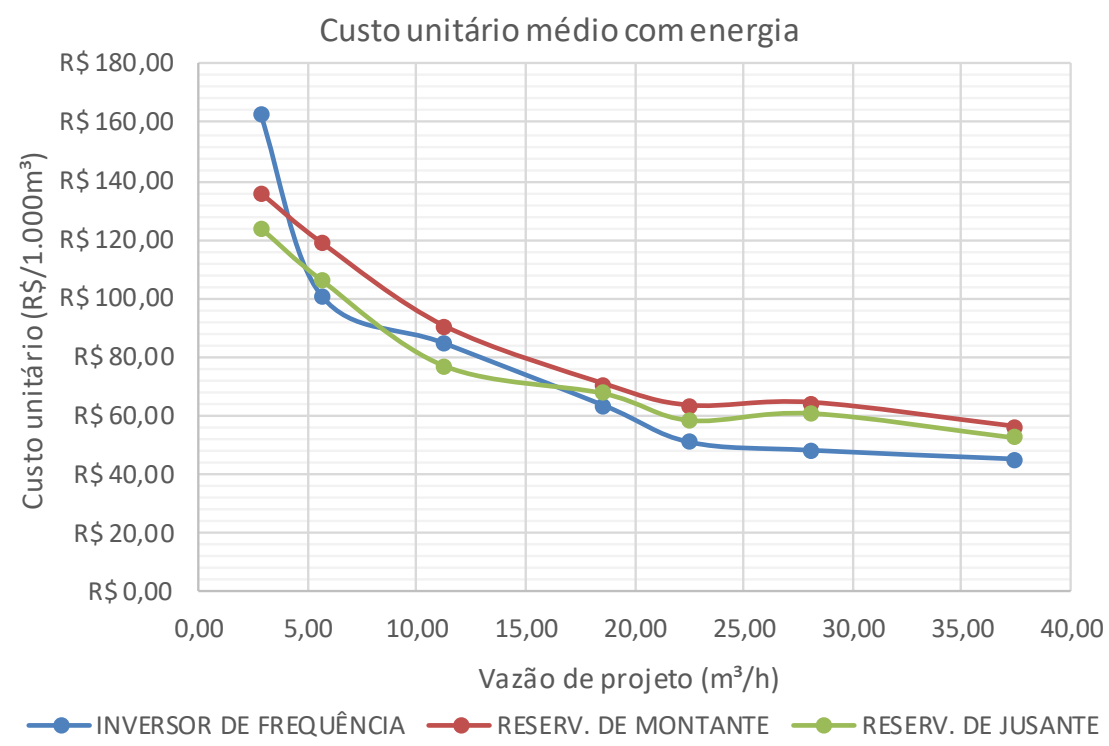

Figura 12 - Custo unitário médio com energia.

O custo para o bombeamento de $1000 \mathrm{~m}^{3}$ para a menor vazão analisada $\left(2,81 \mathrm{~m}^{3} / \mathrm{h}\right)$ é de $\mathrm{R} \$ 163,07$ para o sistema com inversor de frequência, $R \$ 135,71$ para o sistema com reservatório de montante e R\$ 123,92 com reservatório de jusante. Já para a maior vazão calculada $\left(37,46 \mathrm{~m}^{3} / \mathrm{h}\right)$, esses custos são de $R \$ 45,15$ para o sistema com inversor de frequência, $R \$ 55,99$ para o sistema com reservatório de montante e $\mathrm{R} \$ 52,46$ com reservatório de jusante.

\section{CONCLUSÕES}

A partir dos resultados obtidos neste estudo, pode-se concluir que:

- Com exceção da menor vazão analisada, a configuração de sistema com estação elevatória para pressurização da rede com inversor de frequência, sem reservatórios, é a opção com menor consumo energético e menores custos com energia elétrica. 
- As configurações de sistema com reservatório apresentam maior rendimento médio das bombas, visto que elas funcionam sempre próximas do ponto de operação para o qual foram dimensionadas, enquanto o rendimento das bombas com inversor de frequência varia conforme a operação.

- O consumo de energia em função do volume bombeado diminuiu conforme aumento da vazão recalcada, fazendo com que o custo unitário médio com energia elétrica caia conforme o aumento do volume bombeado.

- O sistema com reservatório de jusante apresentou menor gasto de energia do que o de montante. Isso se deve em grande parte ao fato de a distribuição e o consumo ao longo da rede minimizarem as perdas na tubulação entre a EET e o reservatório. Dessa forma, essa opção se mostra adequada para sistemas em que a distância entre a EET e o reservatório é grande, estando a rede de distribuição localizada entre esses dois pontos.

- Para a concepção de sistemas de abastecimento de água, o projetista deverá ponderar as principais vantagens e desvantagens de cada sistema, a fim de decidir qual o mais adequado para cada caso. Também se mostra importante a simulação hidráulica com diferentes opções de abastecimento e diferentes bombas dentre as disponíveis para que sejam tomadas as melhores decisões acerca do projeto.

\section{CONTRIBUIÇÃO DOS AUTORES}

Todos os autores contribuíram de forma igualitária.

\section{REFERÊNCIAS}

BARRY, J. A.; Watergy: Energy and Water Efficiency in Municipal Water Supply and Wastewater Treatment. Cost-Effective Savings of Water and Energy. Alliance to Save Energy, Washington, DC. 2007.

CARVALHO, P. S. O. Controle para bombeamento distribuído com vistas à minimização dos custos energéticos aplicado a sistemas de abastecimento de água. Tese (Doutorado). Universidade Federal da Paraíba, 2012.

COSTA, A.; FIGUEIREDO, M. M. P.; Eficiência Económica na Operação de Estações Elevatórias de Abastecimento de Água (Economic Efficiency in the Operation of Pumping Stations of Water Supply). 4. As Jornadas de Hidráulica, Recursos Hídricos e Ambiente, 2009.

GOMES, H. P.; Eficiência Hidráulica e Energética em Saneamento: Análise Econômica de Projetos. $2^{\mathrm{a}}$ ed., João Pessoa, Brasil, Editora UFPB, 2009.

SHANKAR, V. K. A. et al. A comprehensive review on energy efficiency enhancement initiatives in centrifugal pumping system. Applied Energy, v. 181, p. 495-513, 2016. https://doi. org/10.1016/j.apenergy.2016.08.070

TSUTIYA, M. T.; Redução do custo de energia elétrica em sistemas de abastecimento de água. ABES. São Paulo, SP, Brasil. 185 p. 2001.

YANG Z., WU L. e DONG X, Control System Design For Contant-pressure Water Supply. In: Second International Conference on MultiMedia and Information Technology. Kaifeng, ISBN 9780-7695-4008-5, pp. 55-57. 2010. https://doi.org/10.1109/ MMIT.2010.65. Anais... 